\title{
On the controversy about South African pelagic fisheries: comment on the Letter to the Editor by de Villiers (this issue)
}

\author{
Ulrich Sommer ${ }^{1}$
}

Received: 10 September 2016 / Accepted: 15 September 2016 / Published online: 29 November 2016

(C) Springer-Verlag Berlin Heidelberg 2016

Dear Readers of Marine Biology,

Letters to the Editor are extremely rarely published by Marine Biology. The standard way to express critique of an article published in Marine Biology is and will remain a "Comment," which has to undergo scientific peer review and which is usually followed by a reply by the authors of the original article (see our Instructions for Authors). We have offered this option to de Villiers when he complained on behalf of the South African Pelagic Fishing Industry Association (SAPFIA) about parts of the article by Grémillet et al. (2016a), in particular those components in the discussion which related to pelagic fisheries and its socioeconomic aspects in the study region (de Villiers 2016). De Villiers rejected this option and insisted on publication of his comments as a Letter to the Editor. This controversy is rather atypical, because the major complaints of de Villiers do not relate to the scientific content of the article, but to socioeconomic statements in the discussion which, according to de Villiers, might harm the reputation and impair the marketing chances of South African pelagic fisheries.

A closer examination of the article by Grémillet et al. (2016a) revealed that, regrettably, some of the controversial statements in the article were not sufficiently supported

The online version of the original article can be found under doi:10.1007/s00227-015-2798-2. The Letter to the Editor is found under doi:10.1007/s00227-016-3004-x. An Erratum is found under doi:10.1007/s00227-016-3003-y.

Ulrich Sommer

usommer@geomar.de

1 GEOMAR Helmholtz Centre for Ocean Research Kiel, 24105 Kiel, Germany by the references. Therefore, Marine Biology asked the authors of the original article to write an Erratum. This Erratum (Grémillet et al. 2016b) is now published together with the Letter to the Editor (de Villiers 2016) and this Editorial comment in the current issue of Marine Biology.

The core issues of the controversy concern

1. The fishing quotas of sardine and anchovy stocks in South African shelf waters. While Grémillet et al. advocate a revision of regional fishing quotas for small pelagic fish in order to prevent overfishing and to increase the fitness of the Cape gannets, De Villiers replies that the harvest rates are very conservative and well below those advocated by the international certification bodies. A controversy about overfishing is certainly within the scientific scope of a scientific journal such as Marine Biology. In their Erratum (Grémillet et al. 2016b), the authors have reworded and supplemented some statements published on page 2 and 8 of their paper (Grémillet et al. 2016a) in order to clarify the points criticized by de Villiers (2016). Nevertheless, the dispute cannot be resolved by the data provided by the two parties of our current controversy. The interested reader is invited to the appropriate fisheries journals and reports to find an answer.

2. The impact of the purse-seine fishing activities on the local coastal communities on the west coast of South Africa (Grémillet et al. 2016a, page 8 right column, last paragraph). While Grémillet et al. consider fisheries be only marginable profitable or even not beneficial for the local communities, de Villiers (2016) denies this in his letter and points to the importance of this sector for the local population in this area. Although Grémil- 
let et al. were able to provide better references for their statements concerning the socioeconomic impact, they have decided to shorten the respective section and have withdrawn the statements. This decision has been made in agreement with the Editor-in-Chief, in order to avoid a further controversy, and because the statements were not requisite for the scientific conclusions of the manuscript.

In his letter, de Villiers (2016) demands that the Editorin-Chief of Marine Biology should have applied a better quality control with respect to the controversial statements in Grémillet et al. (2016a).

While the topic of the article is certainly within the scope of Marine Biology, statements on socioeconomic conditions and societal impacts of fisheries are clearly beyond the expertise of our editors and peer reviewers. Marine Policy, just to mention one example, is a much more appropriate journal for such issues and will also have more appropriate reviewers at hand. On the other hand, it is also clear that many articles contain ramifications in their discussion which go beyond the scope of a journal. It is practically impossible to find willing expert reviewers for all these side tracks. What remains is an appeal to authors, to be self-critical when side tracking in their manuscripts and to be very careful when citing references to support statements outside their expertise.

Ulrich Sommer

Editor-in-Chief Marine Biology

\section{References}

De Villiers D (2016) Response to the Marine Biology article 'Starving seabirds: unprofitable foraging and its fitness consequences in Cape gannets competing with fisheries in the Benguela upwelling ecosystem' by Grémillet et al. (2016). doi:10.1007/s00227-016-3004-x

Grémillet D, Péron C, Kato A et al (2016a) Starving seabirds: unprofitable foraging and its fitness consequences in Cape gannets competing with fisheries in the Benguela upwelling ecosystem. Mar Biol 163:35. doi:10.1007/s00227-015-2798-2

Grémillet D, Péron C, Kato A et al (2016b) Erratum to: starving seabirds: unprofitable foraging and its fitness consequences in Cape gannets competing with fisheries in the Benguela upwelling ecosystem. Mar Biol. doi:10.1007/s00227-016-3003-y 